\title{
Dietary conjugated linoleic acid and leucine improve pork intramuscular fat and meat quality*
}

\author{
I.T. Yu' ${ }^{1}$, Y.T. King, S.L. Chen, S.C. Wang, Y.H. Chang and H.T. Yen \\ Animal Technology Institute Taiwan \\ P.O. Box 23, Chunan, Miaoli, 350, Taiwan, ROC
}

(Received 14 July 2006; revised version 13 December 2006; accepted 2 February 2007)

\begin{abstract}
This study investigated which conjugated linoleic acid (CLA) and leucine (LEU) ratio optimized the improvement of pork quality when added to finishing pig diets. A total of 120 finishing pigs were randomly assigned to five treatments, including a control diet and a 2 (LEU 1.0 and 2.0\%) by 2 (CLA 0.5 and $1.0 \%$ ) factorial design. The animals had free access to the diets and water. The pigs were slaughtered at $125 \mathrm{~kg}$ body weight. Growth performance, carcass characteristics, meat quality, sensory evaluation and serum cholesterol levels were measured. Data for each measured factor were analysed using the GLM procedure in SAS (1996). Analytical results revealed the IMF percentage $(1.24,1.04,1.66,2.31$ and $1.61 \%$ for TRT1 to TRT5, respectively) and tenderness $(2.14$, $2.27,2.32,2.57$ and 2.44 for TRT1 to TRT5, respectively) of the loin eye muscle were significantly $(\mathrm{P}<0.05)$ improved by the CLA $0.5 \%$ combined with LEU $2.0 \%$. Other indicators (such as growth performance, meat quality, carcass measurements and serum cholesterol level) were not affected by the LEU and CLA supplementation.
\end{abstract}

KEY WORDS: leucine, conjugated linoleic acids, intramuscular fat, pig

\section{INTRODUCTION}

Pork quality is a composite of numerous factors such as appearance, flavour, marbling, tenderness and juiciness. Marbling ideally 2-4\% intramuscular fat (IMF) improves pork flavour, tenderness and juiciness, and thus is a critical factor for consumers. CLA is a mixture of positional and geometric isomers of linoleic acid combined via two conjugated double bonds at various carbon positions in the

\footnotetext{
* Supported by the Council of Agriculture of the Republic of China, Contract No. 93AS-3.2.1-AD-U1

${ }^{1}$ Corresponding author: ity@mail.atit.org.tw
} 
fatty acid chain. Feeding pigs a diet supplemented with $1.0 \%$ conjugated linoleic acid (CLA) has been demonstrated to improve belly firmness (Eggert et al., 2001), and 2.0\% CLA supplementation increases IMF fat (Dugan et al., 1999; Gatlin, et al., 2002) or marbling on loin muscles (Wiegand et al., 2002), and giving leucine (LEU) has been shown to increase intramuscular fat when added to finishing pig feed (Cisneros et al., 1996; Hyun et al., 2003).

Two primary isomers of CLA found in commercial preparations are cis-9, trans-11 CLA and trans-10, cis-12 CLA.The effects of CLA on lipogenesis seems variable with species, and the mechanisms of action regarding CLA's effects on lipid accumulation in adipocytes are still not well known. It has been shown that the trans-10, cis-12 CLA isomer specifically decreases fatty acid uptake and utilization of exogenously derived fatty acids, thereby limiting substrate for TG synthesis. Mechanisms have been suggested which including trans-10, cis-12 CLA down-regulates the mRNA expression of PPAR $\gamma$ as well as its target genes, fatty acid binding protein $(\mathrm{aP} 2)$ and liver $\mathrm{X}$ receptor $\alpha(\mathrm{LXR} \alpha)$ (Granlund et al., 2003). Trans-10, cis-12 CLA inhibits porcine preadipocyte differentiation by a mechanism that involves the down-regulation of PPAR $\gamma$ and SREBP-1c mRNA. This mechanism is independent of changes in C/EBP $\alpha \mathrm{mRNA}$ abundance and may involve COUP-TF (Brandebourg and Hu, 2005). Trans-10, cis-12 CLA promotes adipocyte delipidation, which may result from ERK-dependent alterations in perilipin and ADRP gene expression, protein activation, and localization (Chung et al., 2005). In contrast the cis-9, trans-11 isomer of CLA fails to inhibit the proliferation and differentiation of pig preadipocytes, and it may even stimulate the differentiation of these cells (Ding et al., 2000; McNeel and Mersmann, 2003). Given that a stimulatory effect of CLA on adipogenesis seems at odds with the ability of CLA to decrease carcass adiposity, the effect of CLA on the hyperplasia of adipocytes in pigs remains controversial.

Leucine (LEU) has been shown to increase intramuscular fat when added to finishing pig feed (Cisneros et al., 1996; Hyun et al., 2003). Studies have demonstrated that high LEU diet reduced pig growth performance; however, conflicting findings were acquired when the LEU level in pig diets was 2-6\% (Edmonds and Baker, 1987; Hyun et al., 2003). Both CLA and LEU increased IMF. Whether different combinations of CLA and LEU applied to pig diet have a booster affect on pork IMF and quality warrants further investigation. This study elucidates the influence on pork quality when finishing diets are supplemented with a combination of CLA and LEU. 


\section{MATERIAL AND METHODS}

\section{Animal and experimental treatment}

A total of 120 finishing pigs (Duroc $\times$ Landrace $\times$ Yorkshire; initial body weight, $60 \mathrm{~kg}$ ) were randomly assigned to the following five treatments, including a control (without supplementing LEU or CLA), and a 2 (LEU 1.0 and 2.0\%) by 2 (CLA 0.5 and $1.0 \%$ ) factorial design. The CLA (BASF Chemical Company, France; purity 64\%) comprised two major CLA isomers (cis-9, trans-11 and trans10, cis-12 CLA). The LEU employed was a form of L-leucine (Ajinomoto Co., Inc. Japan), with purity of $98.5 \%$. All five diets had similar nutrient composition, with the exception of LEU and CLA levels. Table 1 lists the diet formulation

Table 1. Diet formulation and nutrient composition of five treatments

\begin{tabular}{|c|c|c|c|c|c|}
\hline Diets & Control $^{1}$ & $\begin{array}{l}\text { LEU1.0+ } \\
\text { CLA 0.5 }\end{array}$ & $\begin{array}{l}\text { LEU1.0+ } \\
\text { CLA 1.0 }\end{array}$ & $\begin{array}{l}\text { LEU2.0+ } \\
\text { CLA 0.5 }\end{array}$ & $\begin{array}{l}\text { LEU2.0+ } \\
\text { CLA } 1.0 \\
\end{array}$ \\
\hline \multicolumn{6}{|l|}{ Ingredients, $\%$} \\
\hline maize, dent, yellow & 66.9 & 66.4 & 65.9 & 66.4 & 66.2 \\
\hline soyabean meal, solvent ( $44 \%)$ & 22.0 & 21.0 & 21.0 & 19.0 & 19.0 \\
\hline wheat bran & 5.0 & 5.0 & 5.0 & 5.0 & 5.0 \\
\hline molasses & 2.0 & 2.0 & 2.0 & 2.0 & 2.0 \\
\hline tallow & 1.0 & 1.0 & 1.0 & 2.0 & 2.7 \\
\hline limestone & 1.2 & 1.2 & 1.2 & 1.2 & 1.2 \\
\hline dicalcium phosphate & 1.15 & 1.15 & 1.15 & 1.15 & 1.15 \\
\hline salt & 0.5 & 0.5 & 0.5 & 0.5 & 0.5 \\
\hline lysine- $\mathrm{HCl}$ & 0.08 & 0.08 & 0.08 & 0.10 & 0.10 \\
\hline vitamins $^{2}$ & 0.1 & 0.1 & 0.1 & 0.1 & 0.1 \\
\hline minerals $^{3}$ & 0.1 & 0.1 & 0.1 & 0.1 & 0.1 \\
\hline 1-leucine & 0 & 1.0 & 1.0 & 2.0 & 2.0 \\
\hline conjugated linoleic acids & 0 & 0.5 & 1.0 & 0.5 & 1.0 \\
\hline \multicolumn{6}{|l|}{ Nutrient composition, calculated } \\
\hline crude protein, $\%$ & 15.5 & 15.7 & 15.7 & 15.6 & 15.6 \\
\hline digestible energy, kcal/kg & 3350 & 3335 & 3355 & 3342 & 3350 \\
\hline calcium, $\%$ & 0.80 & 0.80 & 0.80 & 0.79 & 0.79 \\
\hline phosphorus, $\%$ & 0.57 & 0.57 & 0.57 & 0.56 & 0.56 \\
\hline lysine, $\%$ & 0.70 & 0.67 & 0.67 & 0.67 & 0.67 \\
\hline
\end{tabular}

${ }_{1}^{1}$ control group with the diet formulation based on maize and soyabean meal without supplementing CLA or LEU

${ }^{2}$ supplied the following vitamin per ton of mixed diet: IU: vit. A 4,000,000; vit. $\mathrm{D}_{3} 800,000$; mg: vit. $\mathrm{B}_{1} 1,250$; vit. $\mathrm{B}_{2} 2,000$; vit. $\mathrm{B}_{6} 300$; vit. $\mathrm{B}_{12} 10$; pantothenic acid 6,000; niacin 15,000; folic acid 100; vit. E 10,000; vit. K3 1,250; choline chloride 50,000

${ }^{3}$ supplied the following minerals per ton of mixed diet: $\mathrm{mg}$ : $\mathrm{Cu}$ 5,000; Fe 25,000; Mn 15,000; I 500; Zn 50,000 
and nutrient composition of the five treatments. In this trial, four pigs were reared per pen with six pens ( 24 pigs) for one treatment. Feed and water were given ad libitum. The pig's body weight and average feed intake of each pen of four pigs were measured at 2-week intervals to assess growth performance. Growth performance was measured based on average daily gain (ADG), feed intake (FI) and feed conversion ratio (FCR). The trial ended when the pig reached $125 \mathrm{~kg}$ body weight.

\section{Serum cholesterol analysis}

Ten $\mathrm{ml}$ of blood was drawn from each pig on the final day of the trial. Following coagulation for one $\mathrm{h}$ at room temperature, blood clots were centrifuged $\left(2500 \mathrm{~g}\right.$ for $20 \mathrm{~min}$ at $\left.4^{\circ} \mathrm{C}\right)$. Serum was then removed and stored at $-20^{\circ} \mathrm{C}$ for subsequent measurement of serum cholesterol concentrations, including total cholesterol (TC), high-density lipoprotein cholesterol (HDL) and triglycerides (TAG), which were performed using enzymatic methods and commercially available kits (VITRO Cholesterol kit, Ortho-Clinical Diagnostics, Johnson and Johnson Company, USA) suited to routine analysis. Very-low-density lipoprotein cholesterol (VLDL) content was derived by dividing TAG by 5 (Friedewald et al., 1972), and low- density lipoprotein cholesterol (LDL) levels were obtained by subtracting HDL and VLDL concentrations from TC.

\section{Carcass measurements and meat quality determination}

Carcass measurements including average back fat, carcass length and loin eye area (LMA) were taken once from each hog at $125 \mathrm{~kg}$ body weight. The LMA was measured at the $10^{\text {th }}$ rib of the carcass. Average back fat was the average of measurements at three points: the first rib, the last rib, and, the last lumbar vertebra. Carcass length was measured from the first rib to the end of the pubic bone.

Meat quality was estimated using IMF percentage, marbling score, water holding capacity (WHC), $\mathrm{pH}$ value and loin muscle colour. Intramuscular fat measurements were performed via the following methods. Fat was measured by hexane extraction using the Soxhlet method (AOAC, 1990). $\mathrm{pH}$ value was measured at room temperature using a $\mathrm{pH}$ meter (PH330/SET-2, WissenschaftlichTechnische Werkstatten, Germany) $12 \mathrm{~h}$ after slaughter. Marbling was measured at the $10^{\text {th }}$ and $11^{\text {th }}$ rib faces using the NPPC 6-point scale (NPPC, 1991). WHC was estimated using the Carver Press method, which utilizes a $1 \mathrm{~g}$ meat sample pressed at 3,000 psi for $3 \mathrm{~min}$ on a $125-\mathrm{mm}$ filter paper to generate two distinct areas: a meat area; and, a water area. The WHC is the ratio of water area to meat area. Low ratio, which is desirable, indicates high water retention ability. $\mathrm{pH}$ 
was measured as the mean from three points, with the measurements being taken directly from a loin chop using a Mettler Toledo electrode (Inlab 427). Finally, colour was measured using the Hunter Lab Color system (MiniScan XE Plus/ Color Flex, Hunter Lab, USA) with a $2.5 \mathrm{~cm}$ objective.

\section{Evaluation of sensory characteristics}

Sensory characteristics were assessed for chops from loin eye muscle cooked in a boiler set at $90-95^{\circ} \mathrm{C}$. Each chop was cut into $1.8 \mathrm{~cm}$ cubes for sensory evaluation. A panel comprising five to seven subjects evaluated the meat for tenderness, flavour and juiciness using a 5-point scale.

\section{Statistical analysis}

Effects of treatment on growth performance, carcass characteristic, meat quality, sensory evaluation and serum cholesterol level were analysed with the GLM procedure of SAS Institute (SAS, 1990). Initially, treatment effects were separated by employing single degree of freedom orthogonal contrasts to compare the control and treatment groups, and to compare LEU 1.0 vs $2.0 \%$ or CLA 0.5 vs $1.0 \%$ and the examine interactions between LEU and CLA. Since the interactions of LEU and CLA were not statistically significant, the effects of treatments was analysed by employing the GLM procedure of SAS as a repeated measure twoway ANOVA. When ANOVA revealed a significant effect, the differences, among treatment groups were tested using Duncan's new multiple range test (Snedecor and Cochran, 1980).

\section{RESULTS AND DISCUSSION}

Table 2 lists the analytical results found for the five treatments on meat quality and sensory evaluation. The experimental results for growth performance, carcass measurements and serum cholesterol concentrations are given in Table 3. The IMF percentage and tenderness of loin eye muscle were higher for the CLA combined with LEU groups (TRT 3, 4 and 5) than for TRT 1, and particularly for TRT 4 $(2.31 \%)$, which had a significantly higher $(\mathrm{P}<0.05)$ IMF percentage than TRT 1 (1.24\%). Meanwhile WHC, $\mathrm{pH}$, colour, juiciness and flavour of loin eye muscle were not significantly influenced by the addition of CLA and LEU. The groups fed CLA and LEU tends to have lighter loin eye muscle colour, and these groups also tender to have higher IMF percentage. Increased fat, typically reflected in a light colour, was associated with increased tenderness. 
Table 2. Effects of CLA and LEU combination on meat quality and sensory evaluation

\begin{tabular}{lccccccc}
\hline Treatment & CTL $^{1}$ & $\begin{array}{c}\text { LEU1.0+ } \\
\text { CLA0.5 }\end{array}$ & $\begin{array}{c}\text { LEU1.0+ } \\
\text { CLA0.5 }\end{array}$ & $\begin{array}{c}\text { LEU1.0+ } \\
\text { CLA 0.5 }\end{array}$ & $\begin{array}{c}\text { LEU1.0+ } \\
\text { CLA 0.5 }\end{array}$ & SE & Significance \\
\hline No. of observation & 24 & 24 & 24 & 24 & 24 & - & - \\
Meat quality & & & & & & & \\
$\quad$ IMF, \% $^{2}$ & 1.24 & $1.04^{\mathrm{b}}$ & $1.66^{\mathrm{ab}}$ & $2.31^{\mathrm{a}}$ & $1.61^{\mathrm{ab}}$ & 0.58 & $*$ \\
$\quad$ WHC $^{3}$ & 1.45 & 1.40 & 1.39 & 1.41 & 1.40 & 0.05 & $\mathrm{NS}$ \\
$\quad$ pH value & 5.54 & 5.58 & 5.53 & 5.53 & 5.57 & 0.02 & $\mathrm{NS}$ \\
$\quad$ colour & 3.56 & 3.00 & 3.00 & 2.75 & 3.38 & 0.53 & $\mathrm{NS}$ \\
& & & & & & & \\
Sensory evaluation & & & & & & & $*$ \\
$\quad$ tenderness & $2.14^{\mathrm{b}}$ & $2.27^{\mathrm{ab}}$ & $2.32^{\mathrm{ab}}$ & $2.57^{\mathrm{a}}$ & $2.44^{\mathrm{ab}}$ & 0.06 & $*$ \\
$\quad$ juiciness & 1.90 & 2.13 & 2.05 & 2.17 & 2.05 & 0.05 & $\mathrm{NS}$ \\
$\quad$ flavour & 2.36 & 2.19 & 2.43 & 2.54 & 2.51 & 0.05 & $\mathrm{NS}$ \\
\hline
\end{tabular}

${ }^{1}$ CTL - control group with the diet formulation based on maize and soyabean meal without supplementing CLA or LEU

${ }^{2} \mathrm{IMF} \quad$ - intramuscular fat percentage

${ }^{3}$ WHC - water holding capacity

* means within the same row with different superscripts differ significantly $(\mathrm{P}<0.05)$; NS - $\mathrm{P}>0.05$

Table 3. Effects of CLA and LEU combination on growth and carcass measurements of pigs and serum cholesterol concentration

\begin{tabular}{lccccccc}
\hline Treatment & CTL $^{1}$ & $\begin{array}{c}\text { LEU1.0+ } \\
\text { CLA0.5 }\end{array}$ & $\begin{array}{c}\text { LEU1.0+ } \\
\text { CLA0.5 }\end{array}$ & $\begin{array}{c}\text { LEU1.0+ } \\
\text { CLA0.5 }\end{array}$ & $\begin{array}{c}\text { LEU1.0+ } \\
\text { CLA0.5 }\end{array}$ & SE & $\begin{array}{c}\text { Signifi- } \\
\text { cance }\end{array}$ \\
\hline No. of pigs & 24 & 24 & 24 & 24 & 24 & - & - \\
& & & & & & & \\
Growth performances & & & & & & & \\
$\quad$ daily gain, g & 794 & 697 & 726 & 720 & 738 & 17.3 & $\mathrm{NS}$ \\
feed intake, kg/d & 2.59 & 2.27 & 2.27 & 2.42 & 2.30 & 0.04 & $\mathrm{NS}$ \\
feed/gain & 3.26 & 3.40 & 3.20 & 3.14 & 3.12 & 0.14 & $\mathrm{NS}$ \\
& & & & & & & \\
Carcass measurements & & & & & & & \\
carcass length, cm & 91 & 93 & 92 & 92 & 92 & 5 & $\mathrm{NS}$ \\
average backfat, cm & 2.86 & 2.49 & 2.63 & 2.87 & 2.66 & 0.20 & $\mathrm{NS}$ \\
loin eye area, in & & & & & & & \\
& 8.19 & 7.88 & 8.44 & 7.14 & 8.68 & 3.36 & $\mathrm{NS}$ \\
Serum cholesterol, mg/dl & & & & & & & \\
total cholesterol & 74.8 & 76.0 & 82.0 & 88.7 & 71.3 & 2.7 & $\mathrm{NS}$ \\
high-density lipoprotein & 16.3 & 15.8 & 17.5 & 15.5 & 15.0 & 0.8 & $\mathrm{NS}$ \\
low-density lipoprotein & 51.5 & 56.3 & 58.8 & 62.0 & 51.0 & 2.1 & $\mathrm{NS}$ \\
triglycerides & 35.5 & 20.0 & 28.3 & 36.3 & 27.0 & 3.4 & $\mathrm{NS}$ \\
\hline
\end{tabular}

NS - P $>0.05$

${ }^{1}$ see Table 1

${ }^{2}$ only six data were used in each treatment due to four pigs in each pen 
Tendernessand IMF percentagewerehigher $(\mathrm{P}<0.05)$ forTRT 4 compared toTRT 1 . The juiciness and flavour of TRT 4 also tended to exceed that of the CTL, revealing that the best combination in terms of improving meat quality is $2.0 \% \mathrm{LEU}$ and $0.5 \%$ CLA (TRT 4). The combination of LEU and CLA fed to group TRT 4 (2.0\% of LEU and $0.5 \%$ CLA) obtained the best results overall. Feeding pigs a diet with $1.0 \%$ CLA has been demonstrated to increase bell firmness (Eggert et al., 2001) while a diet supplemented with 2.0\% CLA increase IMF percentage (Dungan et al., 1999; Gatlin et al., 2002). Meanwhile, study has also showed that diets supplemented with $2.0 \%$ leucine increased $(\mathrm{P}<0.05)$ longissimus fat content and marbling scores in finishing pigs (Cisneros et al., 1996; Hyun et al., 2003). CLA or LEU alone has been shown to improve IMF. This study examined whether supplementing diet with a combination of CLA and LEU may have an additive effect when used in an appropriate ratio. In this work, when diets were supplemented with $0.5 \%$ CLA, increasing the LEU levels from 1.0 (TRT 2) to $2.0 \%$ (TRT 4) increased the IMF percentage significantly $(\mathrm{P}<0.05)$ from 1.04 to $2.31 \%$, respectively, significantly $(\mathrm{P}<0.05)$ exceeding that of the control group (1.24\%). This experimental result is identical to that obtained by Hyun et al. (2003). Pork tenderness displayed a similar tendency, with TRT4 (2.57) significantly $(\mathrm{P}<0.05)$ exceeding that of TRT 1 (2.14). However, when 1.0\% CLA was added to the diets and the LEU level was increased from 1.0 (TRT 3 ) to $2.0 \%$ (TRT 5), IMF and other criteria failed to improve, indicating that high CLA (1.0\%) yielded the best results when combined with low LEU (1\%). Other combinations of CLA and LEU also improved meat flavour, juiciness and tenderness, but the improvements were not statistically significant.

The effect of CLA isomers (cis-9, trans-11 and trans-10, cis-12 CLA) has been variable and occurs by an unknown mechanism (Azain et al., 2003; Dugan et al., 2004). Although hyperplasia of human primary preadipocytes is potently inhibited in vitro by the trans-10,cis-12 CLA isomer (Brown et al., 2003), it has been reported that cis-9, trans-11 CLA fails to inhibit the proliferation and differentiation of pig preadipocytes, and it may even stimulate the differentiation of these cells (Ding et al., 2000; McNeel and Mersmann, 2003). In this trial, the significantly increase of IMF percentage suggested by the boosting effect of cis-9, trans-11 CLA combined with leucine, but the effect of trans-10, cis-12 CLA in this case is still hard to understand and need more study to clarified.

One and 2\% leucine (TRT 2 to TRT 5) were used in this study. High percentages of leucine in pig diets have been shown to retard pig growth rate in some studies (Cisneros et al., 1996; Hyun et al., 2003). However, in this study, 1.0-2.0\% of leucine supplementation in finishing pig diets did not significantly reduce growth rate or feed intake. This result is different from those obtained by Taylor et al. (1984), Cisneros et al. (1996) and Hyun et al. (2003), in which 0.7 and 2.0\% leucine reduced pig growth performance. However, Edmonds and Baker (1987) 
demonstrated that pig growth performance was only hindered with diets containing $6 \%$ leucine, but not with lower levels of supplementation. This discrepancy in experimental results may result from difference in feeding intervals, starting age, body weight or health status of the experimental pigs; for example, Edmonds and Baker (1987) used 4-week-old weaning pigs ( $8 \mathrm{~kg} \mathrm{BW})$, whereas the other three studies used, hogs weighing $25-115 \mathrm{~kg}$. Whether body weight is the primary reason for the different results requires further study.

Regarding loin muscle colour, muscle colour $(\mathrm{P}<0.01)$ was darker when finishing pig diet was supplemented with 2.0\% LEU (Cisneros et al., 1996). However, Hyun et al. (1996) found no influence on loin muscle colour for a diet supplemented with 2.0\% LEU. Joo et al. (2002) and Corino et al. (2003), both of whom supplemented pig diets with $0.25-5.0 \%$ CLA, demonstrated that the colour of loin eye muscle, fat tissue and intramuscular fat did not differ from that in the CTL group. In this work, the finishing pigs eating diets supplemented with both LEU and CLA tended to have lighter loin muscle colour than the control group. Whether CLA has lightens muscle colour thus requires further investigations.

This study found no impact on carcass measurements (carcass length, average back fat and loin eye area) and serum cholesterol (TC, HDL, LDL and TAG) from dietary supplementation with LEU and CLA. Although some studies in experimental animals (hamsters) found a significant cholesterol-lowering effect when fed the trans-10, cis-12 isomer, but not when they were fed the cis-9, trans-11 isomer (de Deckere et al., 1999; Gavino et al., 2000). Most of the numerous studies in experimental animals such as mice, rats, and pigs did not show any effect on plasma cholesterol concentrations. This finding resembles the findings of Taylor et al. (1984), Cisneros et al. (1996), Gatlin et al. (2002) and Hyun et al. (2003), involving LEU or CLA supplementation ranging from $0.7-2.0 \%$ in pig diets. However, these results differ from those of Sun et al. (2004), in which supplementation with $0.125-4.0 \%$ CLA improved loin eye area and reduced back fat thickness.

\section{CONCLUSIONS}

Supplementing LEU and CLA in finishing pig diets improved pork quality (IMF and tenderness) and taste, especially when $0.5 \%$ CLA was combined with $2.0 \%$ LEU (TRT 4), and significantly $(\mathrm{P}<0.05)$ increased intramuscular fat levels of the longissimus muscle thus improving muscle tenderness. The significantly increase of IMF percentage suggested by the boosting effect of $c i s-9$, trans-11 CLA combined with leucine that stimulate the proliferation and differentiation of pig preadipocytes. However, supplementation with CLA and LEU appeared not to affect growth performance, carcass measurement, and serum cholesterol concentrations. 


\section{REFERENCES}

AOAC, 1990. Official Methods of Analysis, Association of Analytical Chemists. $15^{\text {th }}$ Edition. Arlington, VA

Azain M.J., 2003. Conjugated linoleic acid and its effects on animal products and health in singlestomached animals. Proc. Nutr. Soc. 62, 319-328

Brandebourg T.D., Hu C.Y., 2005. Isomer-specific regulation of differentiating pig preadipocytes by conjugated linoleic acids. J. Anim. Sci. 83, 2096-2105

Brown J.M., Boysen M.S., Jensen S.S., Morrison R.F., Storkson J., Lea-Currie R., Pariza M., Mandrup S., McIntosh M.K., 2003. Isomer-specific regulation of metabolism and PPARgamma signaling by CLA in human preadipocytes. J. Lipid Res. 44, 1287-1300

Chung S., Brown J.M., Sandberg M.B., McIntosh M., 2005. Trans-10,cis-12 CLA increases adipocyte lipolysis and alters lipid droplet-associated proteins: role of mTOR and ERK signaling. J. Lipid Res. 46, 885-895

Cisneros F.M.E., Baker D.H., Easter R.A., McKeith F.K., 1996. The influence of short-term feeding of amino acid-deficient diets and high dietary leucine levels on the intramuscular fat content of pig muscle. Anim. Sci. 63, 517-522

Corino C., Magni S., Pastorelli G.,R. Rossi R., Mourot J., 2003. Effect of conjugated linoleic acid on meat quality, lipid metabolism, and sensory characteristics of dry-cured hams from heavy pigs. J. Anim. Sci. 81, 2219-2229

de Deckere E.A., Amelsvoort J.M.V., McNeill G.P., Jones P., 1999. Effects of conjugated linoleic acid (CLA) isomers on lipid levels and peroxisome proliferation in the hamster. Brit. J. Nutr. 82, 309-317

Ding S.T., McNeel R.L., Mersmann H.J., 2000. Conjugated linoleic acid increases the differentiation of porcine adipocytes in vitro. Nutr. Res. 20, 1569-1580

Dugan M.E.R., Aalhus J.L., Jeremiah L.E., Kramer J.K.G., Schaefer A.L., 1999. The effects of feeding conjugated linoleic acid on subsequent pork quality. Can. J. Anim. Sci. 79, 45-51

Dugan M.E., Aalhus J.L., Kramer J.K., 2004. Conjugated linoleic acid pork research. Amer. J. Clin. Nutr. 79, 1212S-1212S

Edmonds M.S., Baker D.H., 1987. Amino acid excesses for young pigs: Effects of excess methionine, tryptophan, threonine or leucine. J. Anim. Sci. 64, 1664-1671

Eggert J.M., Belury M.A., Kempa-Steczko A., Mills S.E., Schinckel A.P., 2001. Effects of conjugated linoleic acid on the belly firmness and fatty acid composition of genetically lean pigs. J. Anim. Sci. 79, 2866-2872

Friedewald W.T., Levy R.I., Fredrickson D.S., 1972. Estimation of the concentration of low-density lipoprotein cholesterol in plasma, without use of the preparative ultracentrifuge. Clin. Chem. 18, 499-502

Gatlin L.A., See M.T., Larick D.K., Lin X., Odle J., 2002. Conjugated linoleic acid in combination with supplemental dietary fat alters pork fat quality. J. Nutr. 132, 3105-3112

Gavino V.C., Gavino G., Leblanc M.-J., Tuchweber B., 2000. An isomeric mixture of conjugated linoleic acids but not pure cis-9, trans-11-octadecadienoic acid affects body weight gain and plasma lipids in hamsters. J. Nutr. 130, 27-29

Granlund L., Juvet L.K., Pedersen J.I., Nebb H.I., 2003. Trans10, cis12-conjugated linoleic acid prevents triacylglycerol accumulation in adipocytes by acting as a PPARgamma modulator. J. Lipid Res. 44, 1441-1452

Hyun Y., Ellis M., Bressner G., Baker D., 2003. Effect of Dietary leucine levels on carcass composition, meat quality, and growth performance in finishing pigs. Can. J. Anim. Sci. 83, 315-318 
Joo S.T., Lee J.I., Ha Y.L., Park G.B., 2002. Effects of diet on lipogenic enzyme activities and on the composition of the lipid oxidation and water holding capacity of pork loin. J. Anim. Sci. 80, $108-112$

McNeel R.L., Mersmann H.J., 2003. Effects of isomers of conojugated linoleic acid on porcine adipocyte growth and differentiation. J. Nutr. Biochem. 14, 266-274

NPPC, 1991. Procedures to Evaluate Market Hogs. National Pork Producers Council, Des Moines, IA (USA)

SAS Institute, 1996. SAS User's Guide: Statistics. SAS Institute, Cary, NC

Snedecor G.W., Cochran W.G., 1980. Statistical Methods. $7^{\text {th }}$ Edition. Iowa State University Press, Ames, IA

Sun D., Zhu X., Qiao S., Fan S., Li D., 2004. Effects of conjugated linoleic acid levels and feeding intervals on performance, carcass traits and fatty acid composition of finishing barrows. Arch. Anim. Nutr. 58, 277-286

Taylor S.J., Cole D.J.A., Lewis D., 1984. Amino acid requirement of growing pigs. 5. The interaction between isoleucine and leucine. Anim. Prod. 38, 257-261

Wiegand B.R., Sparks J.C., Parrish Jr. F.C., Zimmerman D.R., 2002. Duration of feeding conjugated linoleic acid influences growth performance, carcass traits, and meat quality of finishing barrows. J. Anim. Sci. 80, 637-643 